\title{
Aproximación a la dimensión dialogal del misterio-espanto humano. La antropología teresiana desde la finitud ${ }^{1}$
}

\author{
Agustina Serrano \\ FACULTAD DE TEOLOGÍA \\ PONTIFICIA UNIVERSIDAD CATÓLICA DE CHILE \\ aserranp@uc.cl
}

Resumen: Con ocasión del quinto centenario del nacimiento de santa Teresa de Ávila y en el contexto de los cincuenta años del Concilio Vaticano II se ofrece el presente artículo como una contribución al enigma de la finitud. Para Teresa el "espanto" invita a entrar en su latente antropología que puede ser caracterizada de unificada, relacional y comprometida gracias a una pneumatología humanizante. Leyendo los textos teresianos en clave dialogal es posible poner de manifiesto que el espanto humano se despliega a largo de la existencia como misterio de la unidad en la diversidad que remite a la alteridad y lanza hacia un proyecto esperanzado.

Palabras clave: Antropología, Espíritu, Misterio, Diálogo, Espanto.

Abtsract: On the occasion of the Fifth Centenary of the birth of Saint Teresa of Avila and in the context of the 50th anniversary of the Vatican Council II, this article is offered as a contribution to the enigma of finiteness. For Teresa "fright" invites into her latent anthropology, which can be characterised as unified, relational and committed through a humanizing pneumatology. Reading the theresian text in a dialogical key, it is possible to reveal that the human fright is unfolded along the existence as a mystery of unity in diversity which refers to otherness and impels towards a hopeful project.

Keywords: Anthropology, Spirit, Mystery, Dialogue, Fright.

1 Con motivo del primer quinquenio de la investigación doctoral (2010-2015) se realiza una relectura en camino hacia una antropología teológica dialogal en el Castillo Interior de Santa Teresa de Ávila. El Espíritu Santo, gracias a la compenetración de amor y razón, ilumina el misterio ("espanto") del ser humano; es decir, gracias a una pneumatología teresiana se descubre una latente antropología capaz de dar luz al enigma de la finitud. Un versión abreviada se publicará en las Actas del Congreso sobre Las Moradas. Ávila, España 2013. La edición usada es la de J.V., RodríGUEZ, Castillo Interior o Las Moradas (Editorial de Espiritualidad, Madrid 19997, 252 p.). 


\section{INTRODUCCIÓN}

Con ocasión del quinto centenario del nacimiento de santa Teresa de Ávila y en el contexto de los cincuenta años del Concilio Vaticano II se ofrece el presente artículo como una contribución al desentrañamiento de la antropología teológica latente en la obra culmen de la mística y poeta abulense del siglo XVI, para resaltar lo que Juan Noemi señalara en su momento respecto "al lugar de eminencia que ocupa una tal investigación en la estructura académica de una Facultad de Teología, no en su formalidad sino en su significación material"2.

El tema es una aproximación a la siempre enigmática relación dialogal del ser humano con Dios, con los otros y con una misma -como afirma Teresa-. A través del estudio se pretende entrar "con los pies descalzos", sabiendo que el pensamiento sobre el misterio no suele amoldarse a lo establecido, sino que penetra como una palabra apropiada y plural, la que inunda como una comunicación creativa. Por eso es necesario el respeto para interpretar buscando "una inteligencia de lo eterno en la transitoriedad de lo histórico"; es decir, la finalidad es "pensar la fe" desde la persona libre y responsable que vive la existencia cristiana en la historia "fundada en el misterio de la persona de Jesucristo"3.

El tema estudiado es un esbozo de la antropología pneumatológica teresiana en El Castillo Interior. Metodológicamente se lee la obra desde el texto y más allá del texto con la perspectiva que da la hipótesis según la cual el Espíritu Santo ilumina el misterio del ser humano. Para ello se estudian los términos significativos que van señalando el camino de acceso a la complejidad de la relacionalidad de lo humano; es decir, una relectura analítica del pensamiento teresiano desde las coordenadas de espíritu, amor-razón y espanto. La lectura en profundidad de los textos relevantes nos va sugiriendo un índice provisorio desde las categorías antropológicas de creación, salvación y plenificación. Y en relación dialogal con las tres andanzas existenciales que el ser humano realiza en su vida $^{4}$.

2 J. Noemi, "En la presentación del libro de Agustina Serrano", Facultad de Teología de la Pontificia Universidad Católica de Chile, mayo 2012.

J. Noemi, "En la presentación...".

4 A. Serrano, "Antropología teológica latente en el Castillo Interior de Santa Teresa de Jesús”, Revista Teresianum 63 (2012) 191-211. 
En esta ocasión partimos desde la luz que ilumina de la definitividad. Cuando Teresa escribe ya está llegando al final de su camino. De ese modo es posible ir dando cuenta desde una pneumatología humanizadora (1) la posibilidad de formular una antropología latente (2) que ilumine el enigma de la finitud como espanto (3).

Por lo tanto, el artículo se estructura, en primer lugar (1), a partir de una pneumatología humanizadora que presenta el misterio-espanto de lo humano, esclareciéndose desde el misterio trinitario. Es la etapa de la quinta a la séptima morada, es la vida cristiana donde el Espíritu del Padre y del Hijo regala al ser humano la experiencia de unión con el Amado. El Espíritu de Dios dona el ser (1.1), el Espíritu del Señor humaniza (1.2) y el Espíritu Santo plenifica (1.3). Desde el boquete de lo definitivo llega la luz iluminadora.

De igual manera se da el segundo capítulo: una antropología latente (2) en la morada intermedia - puede ser leída como etapa de medianía de la vida- trata de sacar a la luz el misterio que asombra y sobrecoge (espanto). El ser humano que ama y conoce se descubre en proceso dialógico de humanización a través de su ser creatural dignificado por la razón y el amor (2.1); potenciado por la libertad de hijo (2.2.); y que por gracia se va divinizando (2.3).

Finalmente, en el capítulo tercero, el enigma de la finitud como espanto (3) en las moradas iniciales nos hablan de un ser humano como misterio que dialoga con la diversidad (3.1.), en relacionalidad (3.2) y hacia la definitividad (3.3).

En síntesis, el misterio humano se devela gracias al Espíritu que dona el ser (1.1), humaniza (1.2) y plenifica (1.3). De modo que el sujeto se descubre como un ser dignificado (2.1) y potenciado (2.2) hacia la divinización mediante el diálogo (2.3). Así, el misterio de la unidad en la diversidad (3.1) remite a la alteridad del ser humano con Dios (3.2) y deviene en un proyecto esperanzado (3.3).

Teresa contempla un ser humano valiosísimo "un diamante [...] un paraíso adonde dice él [Dios] tiene sus deleites" ${ }^{5}$. Todas las dimensiones de lo humano "se han de considerar con plenitud y anchura y grandeza"6. Se trata de dar cuenta de la vida finita que espanta a lo largo de un iti-

$1 \mathrm{M} 1,1$.

$6 \quad 1 \mathrm{M} 2,8$. 
nerario con tres momentos existenciales cronológicos -inicio, meseta y final- que pueden ser leídos desde el momento fundamental y final del proceso. Esto es la ausencia inaccesible al configurarse como "presencia de [Dios que...] hace gran espanto al alma"7.

De esta manera, el espanto teresiano es entendido como "estupor profundo, mezcla de conocimiento admirativo y emotividad visceral"8. Este concepto estructura los tres capítulos al vertebrar las andanzas de la existencia humana. De modo que se ilumina el espanto gracias al Espíritu Santo que habitando al ser humano lo hace Su morada, por lo que somos templo del Espíritu Santo ${ }^{9}$. En el segundo capítulo, se da sentido al espanto-misterio de la finitud revelando que no somos creaturas sin más; tenemos una gracia especial debido a la filiación en el Hijo. Finalmente, en el capítulo tercero, el espanto se sitúa en relación con el misterio humano que se vislumbra como lo tremendo y lo fascinante. Así en la clave creacional el espanto es asombro y sobrecogimiento; en la clave soteriológica el espanto se presenta como la admiración y el desafío; y en la escatológica el espanto adquiere los matices del estupor y el pavor.

\section{UNA PNEUMATOLOGÍA HUMANIZADORA}

En torno al tiempo del Concilio Vaticano II, en los años sesenta, Rahner anunciaba la nueva condición del cristiano en nuestro tiempo el siglo XXI y convidaba a una relación personal e inmediata con Dios, a la experiencia del misterio, ya que "cabría decir que el cristiano del futuro o será un "místico», es decir, una persona que ha "experimentado» algo o no será cristiano. Porque la espiritualidad del futuro no se apoyará ya en una convicción unánime, evidente y pública, ni en un ambiente religioso generalizado, previos a la experiencia y a la decisión personales"10.

$6 \mathrm{M} 9,5$.

8 T. Álvarez, "Una palabra al lector”, en A. Serrano, Una propuesta de antropología teológica en el Castillo Interior de Santa Teresa de Ávila, Institución Gran Duque de Alba, Ávila 2011, 253 p., 20.

9 1Cor 3, 16: “¿No sabéis que sois templo de Dios y que el Espíritu de Dios habita en vosotros?; 1Cor 6, 19: “¿O no sabéis que vuestro cuerpo es templo del Espíritu Santo, que está en vosotros...?”.

10 Cf. K. Rahner, "Espiritualidad antigua y actual, en Escritos de Teología, vol. VII, Taurus Ediciones, Madrid 1969, 13-35. p. 25. 
Se contempla el misterio del ser humano revelándose gracias a una antropología trinitaria. El ser humano se va humanizando plenamente gracias al Padre que dona el Espíritu del Hijo, quien habitando en la hondura ilumina el espanto de lo humano. Se llega a la etapa final de la vida cristiana tras un largo recorrido, donde el Espíritu del Padre y del Hijo regala al ser humano la unión con el Amado ${ }^{11}$.

En la definitiva fase del proceso de unión con Dios trino y uno, se presenta la acción del Espíritu de Dios que donando el ser lo mantiene hasta la plena humanización. Mirando las tres perspectivas: la creación, la salvación y la escatología; se puede afirmar que el ser humano desde el primer momento que recibe su ser $(6 \mathrm{M} \mathrm{3,17)}$ es capacitado para la unión con Dios viviendo la vida de Cristo (7M 2, 5), y que sabiéndose habitado por el Espíritu se reconoce morada de la trinidad (7M 1, 6).

El espíritu de Dios dona el ser a su imagen y semejanza; es decir, se hace presente gestando la creación. También el espíritu del Señor humaniza a través de la encarnación salvadora que conduce la historia hacia la plenitud; y, además, el Espíritu Santo seguirá presente comunicando al Dios trinitario hasta la plenificación total ${ }^{12}$.

El hilo conductor se constituye a partir de la palabra clave de espíritu: espíritu de Dios, espíritu del Señor y Espíritu Santo, vocablos esenciales mediante los cuales Teresa pone de manifiesto una antropología evoluti-

11 Cf. A. Serrano, Una propuesta..., 253 p. Cf. J.L. Astigarraga - A. Borrell, Concordancias de los escritos de Santa Teresa de Jesús, 2 vol. (Editoriales OCD, Roma 2000, 3052 pp.). En las siete moradas teresianas encontramos trece textos con los vocablos "espíritu de Dios, del Señor y Santo". Espíritu de Dios: 6M 1, 8; 6M 3, 9; 6M 3, 17. Espíritu del Señor: 4M 1, 3; 6M 3, 11 (confesor); 6M 3, 18; 7M 2, 5; $5 \mathrm{M} \mathrm{4,} \mathrm{10.} \mathrm{Y} \mathrm{los} \mathrm{textos} \mathrm{sobre} \mathrm{el} \mathrm{Espíritu} \mathrm{Santo:} \mathrm{4M} \mathrm{1,} \mathrm{1;} 5 \mathrm{M} 2,3 ; 5 \mathrm{M} \mathrm{4,} \mathrm{11;}$ $6 \mathrm{M} \mathrm{1,} \mathrm{1;7M} \mathrm{1,} \mathrm{6.} \mathrm{En} \mathrm{las} \mathrm{tres} \mathrm{primeras} \mathrm{moradas} \mathrm{está} \mathrm{ausente} \mathrm{el} \mathrm{término.} \mathrm{La} \mathrm{sexta}$ morada es la más rica en su presencia con seis textos. Las moradas segunda y quinta presentan dos textos cada una, y la séptima con tres. En el trabajo se estudian los textos $6 \mathrm{M} \mathrm{3,17;7M} \mathrm{2,} \mathrm{5;} \mathrm{y} \mathrm{7M} \mathrm{1,} 6$ (texto clave de la inhabitación trinitaria).

Cf. A. Serrano, Una propuesta..., 75 nota 131; 153-155; y 195-199. La recapitulación aparece en $E f 1$, 9-10: "el Misterio de su voluntad... para realizarlo en la plenitud de los tiempos: hacer que todo tenga a Cristo por Cabeza”. Cf. A. SErrano, "Educación para la gratuidad mediante la comunicación: la metáfora pedagógica. A la mística por las letras. Aproximación al Castillo Interior de Santa Teresa de Ávila (1515-1582)". IV Coloquio ALALITE, Literatura teología con diálogos e provocacoes, Organiza PUC-SP, Brasil 1-3 octubre 2012. ISSN 2316-9346. 
va, personalista y esperanzada desde su perspectiva mística desarrollada en las tres últimas moradas $(5-7 \mathrm{M})$.

\subsection{El espíritu de Dios dona el ser}

En el texto teresiano, el espíritu de Dios proporciona elementos para poder formular una pneumatología humanizadora en perspectiva creacional. Así el espíritu de Dios se hace presente generando el ser a su imagen y semejanza, lo que refleja una antropología evolutiva ${ }^{13}$.

La experiencia de un Dios gratuito que regala la gracia de la existencia provoca en el ser humano la humildad y la confianza. El Dios trino y uno creador comienza regalando la existencia, continua manteniendo todo lo creado y lleva a la máxima humanización en el encuentro definitivo con Él.

La criatura finita y salvada que es consciente del don de Dios relativiza su persona. A mayor cercanía de Dios más se descubre la propia verdad y la finitud no espanta, sino que invita a la confianza en el amor misericordioso de Dios. De esta manera, la antropología latente teresiana se descubre a través de la creaturalidad como develadora de la presencia de $\operatorname{Dios}^{14}$.

Por un lado, la soberbia deshumaniza; en cambio, el verdadero autoconocimiento acrecienta la conciencia del pecado y la negación del egoísmo. Además, el olvido de sí permite la entrega al proyecto divino. Así, todo el ser de modo consciente se abandona en Dios sabiendo su finitud y limitación. Se presenta una nueva manera de pensar y de racionalidad amorosa que confronta y desafía la lógica dominante ${ }^{15}$.

13 Cf. 6M 3, 17. El texto teresiano concentra los cuatro términos relevantes de lo humano; un sujeto que evolutivamente se va configurando en integralidad.

14 La doctrina de la creación fundamenta una teología de la historia sustentada en que el proceso de lo creado ayuda a ver la creación como hecho salvífico que está orientado a la nueva creación $(6 \mathrm{M} 3,17)$. Lo creado es capaz del Espíritu y si lo acoge se va transformando hasta la plena humanización, la plenificación en la nueva creación. Este aspecto unido a una cristología cósmica en Pb y Jn (6M 3, 9, encarnación) y al tema de la temporalidad del acto creador y el fin de la creación (6M 1, 8, tiempo) ayudan a esa teología de la historia.

15 Cf. 6M 3, 17. "Si son favores y regalos del Señor, mire con atención si por ello se tiene por mejor; y, si mientras mayor palabra de regalo no quedare más confundida, crea que no es espíritu de Dios; porque es cosa muy cierta que cuando lo es, mientras mayor merced le hace muy más en menos se tiene la misma alma y más acuerdo 
La creaturalidad como categoría de antropología teológica remite a un ser capaz de apertura al Espíritu de Dios; un ser con potencialidades para el cumplimiento del proyecto divino que se sabe sostenido por Dios. La criatura creada a imagen y semejanza de Dios es un ser abierto a la transformación perfeccionadora: desde la humildad no se considera superior y tanta gracia le desborda. Todas las dimensiones humanas de la criatura, entendimiento, memoria y voluntad, pueden ser enfocadas desde el proyecto de amor de Dios y así la persona se va configurando con Cristo que lleva a cumplimiento la voluntad de Dios. La experiencia de la gracia genera la humildad "porque es cosa muy cierta que cuando lo es, mientras mayor merced le hace muy más en menos se tiene la misma alma”. Así es posible considerar a los otros como superiores y dedicarse en exclusiva a la vocación recibida ${ }^{16}$. De esa manera, se incrementa la conciencia de pecado y el ser humano vive en un estilo de permanente paradoja de "temor y certidumbre" porque "más acuerdo trae de sus pecados y más olvidada de su ganancia [...] y con más temor anda de torcer en ninguna cosa su voluntad, y con mayor certidumbre de que nunca mereció aquellas mercedes". El ser humano es creado capaz de reconocer su inmerecimiento cuando se sabe y se siente habitado por el espíritu de Dios. El ser humano recibe la gracia sobreabundante que le permite el reconocimiento y el agradecimiento. La creatura descubre que cuando pretende autoprocurarse la salvación solo consigue el alejamiento de Dios, lo que es un "infierno".

Seguidamente, se anuncia el amor de Dios que regala la gracia sobreabundante para la liberación del pecado. De todos modos, la vida humana transcurre entre el "temor" y la "certidumbre"; el miedo y la sospecha, por un lado, y la seguridad y la esperanza por otro ${ }^{17}$.

trae de sus pecados y más olvidada de su ganancia y más empleada su voluntad y memoria en querer solo la honra de Dios, ni acordarse de su propio provecho, y con más temor anda de torcer en ninguna cosa su voluntad, y con mayor certidumbre de que nunca mereció aquellas mercedes, sino el infierno".

16 La conciencia de la propia finitud apareja una valoración de los otros como superiores desde la Palabra de Dios. Así Flp 2, 3; "Nada hagáis por contienda o por vanagloria; antes bien con humildad, estimando cada uno a los demás como superiores a él mismo"; Rm 12, 3: "por la gracia que me es dada, os digo: no os estiméis en más de lo que conviene; tened más bien una sobria estima según la medida de la fe que otorgo Dios a cada cual" (Biblia de Jerusalén).

17 Cf. 6M 3, 17. "Como hagan estos efectos todas las cosas y mercedes que tuviere en la oración, no ande el alma espantada sino confiada en la misericordia del Señor, 
Se invita a la criatura a ir transitando con serenidad y entrega de tal modo que "no ande el alma espantada". Se trata de una existencia confiada en la fidelidad de Dios que nunca falla y que fortalece al ser humano para alojarse en la verdad ya que "no dejará al demonio que la engañe".

La condición creatural remite a un ser que reconoce que Dios le sostiene sin mérito por su parte, por pura gratuidad y por eso puede vivir libremente y confiado sin espanto (asombro y sobrecogimiento). La autora defiende la eficacia de la oración, diálogo amoroso con quien le ama, asegurando que quien vive desde la gratuidad saborea la libertad, porque sabe de la fidelidad divina: "tratar de amistad, estando muchas veces tratando a solas con quien sabemos nos ama"18. La persona asume responsablemente la fidelidad desde la experiencia del amor misericordioso de $\operatorname{Dios}^{19}$, que la acompaña en su cotidiano existir y así puede vivir en la verdad, porque Dios concede la fortaleza para vencer el mal. Teresa en V 23, $15^{20}$ cita el texto paulino de 1 Cor $10,13^{21}$ para que en los momentos de oscuridad y dolor la persona se conduzca con una actitud crítica ante el engaño del mal.

que es fiel y no dejará al demonio que la engañe, aunque siempre es bien se ande con temor".

$18 \mathrm{~V} 8,5$.

19 Cf. Salmo 100, 5. "Yahveh es bueno. Para siempre es su misericordia, y su fidelidad por todas las generaciones".

$20 \mathrm{~V} 23,15$. "A mí me dio tanto temor y pena que no sabía qué me hacer. Todo era llorar. Y estando en un oratorio muy afligida, no sabiendo qué había de ser de mí, leí en un libro, que parece el Señor me lo puso en las manos, que decía san Pablo que era Dios muy fiel, que nunca a los que le amaban consentía ser del demonio engañados (1Co 10, 13). Esto me consoló muy mucho. Comencé a tratar de mi confesión general y poner por escrito todos los males y bienes; un discurso de mi vida lo más claramente que yo entendí y supe, sin dejar nada por decir. Acuérdome que, como vi después que lo escribí tantos males y casi ningún bien, que me dio una aflicción y fatiga grandísima. También me daba pena que me viesen en casa tratar con gente tan santa como los de la Compañía de Jesús, porque temía mi ruindad y parecíame quedaba obligada más a no lo ser y quitarme de mis pasatiempos, y si esto no hacía, que era peor; y así, procuré con la sacristana y portera no lo dijesen a nadie. Aprovechóme poco, que acertó a estar a la puerta cuando me llamaron quien lo dijo por todo el convento. Mas ¡qué de embarazos pone el demonio y qué de temores a quien se quiere llegar a Dios!".

21 1Cor 10, 13: "No os ha sobrevenido ninguna tentación que no sea humana; pero fiel es Dios, que no os dejará ser tentados más de lo que podéis resistir, sino que dará también juntamente con la tentación la salida, para que podáis soportar”. 
En síntesis, la criatura devela a Dios; es su representante visible en el mundo, es el rostro de Dios para los demás. El ser humano cuando asume su ser creado se sabe conducido por Dios en toda su existencia y acogiendo el plan de Dios crea un estilo de vida dialogante que testimonia el amor encarnado de Dios en Jesús y convoca a otros a vivir el mensaje en comunidad eclesial.

\subsection{El espíritu del Señor humaniza encarnándose}

El espíritu del Señor aparece en el texto que sigue dando datos para sistematizar una posible pneumatología humanizadora. Ahora, en perspectiva salvífica, el espíritu del Señor está presente en la historia a través de la encarnación aproxima a una antropología personalista ${ }^{22}$.

La encarnación es el primer paso hacia la mayor humanización, pero también hacia la divinización, poniendo de manifiesto que el ser humano es una unidad sustancial susceptible de configurarse al estilo de Jesús gracias al espíritu del Señor. Como dice la autora, la unión del ser humano con Dios progresa hasta la transformación de la propia existencia en la vida de Cristo. De tal modo que la profunda antropología teresiana comprende lo humano como una particularidad existencial. Es por esto que, gracias a la configuración con Cristo, el ser humano toma conciencia de su identidad de sujeto y persona.

La autora, en continuidad con San Pablo, afirma que el ser humano se va configurando con Cristo hasta "hacerse un espíritu con Él (1 Cor $6,17)$ ", lo que es posible porque el ser humano es unidad de espíritu y materia. El Señor se une al ser humano en una comunión matrimonial en la que "serán los dos uno solo" (Mt 19, 5) 23 .

La antropología teresiana se basa en la concepción paulina de la antropología cristiana valoradora de la sexualidad, del cuerpo y en defini-

22 Cf. 7M 2, 5.

23 Cf. 7M 2, 5. "Quizá es esto lo que dice San Pablo: el que se arrima y allega a Dios, hácese un espíritu con El (1 Cor 6, 17), tocando este soberano matrimonio, que presupone haber llegado su Majestad al alma por unión”.

El evangelio de Mt 19, 5, recoge que ante la pregunta sobre el divorcio, Jesús responde desde el origen (Gn 1, 27; 2, 24). El texto de 1 Cor 6, 17: "el que se une al Señor, se hace un solo espíritu con Él”, la vida conyugal vincula en unión espiritual, Rm 8, 9-1, con Cristo, Ef 5, 23; 6, 20; 7, 23; Rm 3, 24; 6, 15. 
tiva del ser humano en su existencial concreto ${ }^{24}$. El seguimiento de Jesús implica un irse configurando a su estilo y manera de ser humano auténtico. El cristiano puede irse moldeando a este proyecto antropológico gracias a la presencia del espíritu del Señor. Teresa compara el modo de estar Dios en el ser humano con la unión matrimonial -el núcleo de lo dialogal está en el "matrimonio espiritual", signo culmen de diálogo-y “presupone haber llegado su Majestad al alma por unión”.

Teresa testifica que su vida es ya Cristo y morir es una ganancia (Flp $1,21)$ porque ella se ha transformado y experimenta a Cristo viviendo en ella. Tal certeza devela la unión más profunda que se pueda desear. Cuando el Señor Jesús mora en el ser humano se comienza a gozar la vida divina y se va creciendo en cotas de humanidad hasta identificarse con el hombre perfecto, pleno y cabal en quien la antropología llega a su culmen, haciéndose cristología $\mathrm{a}^{25}$.

La vida en Cristo crece muriendo, así como el grano de trigo al caer en la tierra. La paradoja vida y muerte remite a un proceso salvífico que desemboca en la felicidad producida por un "grandísimo gozo" que el ser humano puede experimentar. La imagen de la "mariposilla" nacida de la transformación del gusano ahora nuevamente sufre la metamorfosis. Así el ser humano va pasando por todo ese cambio transformante hasta afirmar que su vida es Cristo y el morir es la máxima ganancia, porque ya atisba el encuentro definitivo.

El texto al que Teresa alude (1 Cor 6, 17), refleja la antropología paulina de la divinización "el que se une al Señor, se hace un espiritu con El'. El ser humano se manifiesta ante los otros y ante el mundo como un ser (carne animada) mundano que vive en la temporalidad; y también es un ser (alma encarnada) capaz de transcender el mundo y el tiempo y establecer relaciones con Dios, porque el ser humano es imagen de Dios que se va transformando hasta la perfecta humanización.

24 Pablo llama al cristiano miembro de Cristo y templo del Espíritu Santo. En 1Cor $16,12-20$ se encuentran algunos elementos germinales de la valiosa antropología paulina.

25 Cf. 7M 2, 5. "Y también dice: mihi vivere Christus est, mori lucrum; así me parece puede decir aquí el alma, porque es adonde la mariposilla, que hemos dicho, muere, y con grandísimo gozo, porque su vida es ya Cristo". Flp 1, 21: "para mí la vida es Cristo y la muerte una ganancia", se presenta la muerte no con miedo sino como un paso a una nueva vida de felicidad y gozo en el Señor en quien se cumplen todas las promesas. 


\subsection{El Espíritu Santo plenifica}

Cuando la abulense escribe sobre el Espíritu Santo remite a una pneumatología humanizadora contemplada desde la escatología. El Espíritu Santo seguirá presente a través de la inhabitación trinitaria. Esto es, en forma de una antropología esperanzada ${ }^{26}$.

La plenificación en que Cristo llegue a ser uno en todo (Ef 1, 10), colma y llena de esperanza toda la realidad porque el origen y el final al estar sustentados en Dios se orientan hacia un buen desenlace gracias al Espíritu Santo.

El ser humano experimenta, entiende y expresa la gracia que le posibilita la comprensión del misterio trinitario y le regala la toma de conciencia de la inhabitación. La antropología teresiana en este punto se hace optimista al máximo porque se funda en el protagonismo divino. Es el mismo Dios quien suscita y sostiene la libertad finita y así el ser humano se lanza a los mayores desafíos para que su humanización se logre y se cumpla a cabalidad dentro del proyecto amoroso de Dios.

En la séptima morada, se explica la liberación del conocimiento y la persona atisba el misterio trinitario. La gracia puede ser vista y entendida por el ser humano de la misma manera que la verdad se vislumbra con el resplandor del "alma inflamada" 27.

Al final del proceso se habla de "visión intelectual" explicando la caída de "las escamas de los ojos" 28 para que el ser humano "vea, y entienda algo de la merced" de la revelación del Dios trinitario. El misterio de comunión y entrega a Dios se va purificando, iluminando y se libera de dudas, malicias y todo lo que le impide comprender. Entonces la verdad se le patentiza de manera diversa a las etapas anteriores. Decir que la iniciativa y la resolución estén garantizadas en un Dios que es fiel, posibilita que el ser humano participe y colabore en el plan salvífico de toda

26 Cf. 7M 1, 6. El texto es riquísimo en términos relevantes, así están presentes el Espiritu Santo, el ser humano como ámbito de la presencia de Dios, el amor y la razón y el misterio que se va develando como tremendo y fascinante.

27 Cf. 7M 1, 6. "Aquí es de otra manera: quiere ya nuestro buen Dios quitarla las escamas de los ojos, y que vea, y entienda algo de la merced que le hace, aunque es por una manera extraña y metida en aquella morada por visión intelectual, por cierta manera de representación de la verdad".

28 Hch 9, 18: "Al instante cayó de los ojos de Saulo algo como escamas, y recobró la vista. Se levantó y fue bautizado". 
la creación hasta la plenificación. La conversión de Saulo que le libera de "escamas" en Hch 9, 18 y el texto de Jn 14, 23 ayudan a Teresa a comunicar la inefabilidad de la experiencia de lo definitivo en medio del devenir de la historia. Le ayudan a decir que la transcendencia acampa en la inmanencia y así el final es esperanzador porque Dios ama su obra.

El ser humano se capacita por la gracia para la comprensión del misterio trinitario que se le revela mediante signos entendibles. Esto se consigue debido a una claridad que penetra toda obscuridad revelando como confidencia la esencia del misterio ${ }^{29}$.

La teología teresiana toma altos vuelos. El ser humano recibe en "su espíritu" tal luz y claridad que enardecida toda la persona queda "inflamada" de tal modo que el ser humano coopera "en el logro de los fines". Así de manera ardiente y encendida llega a comprender que, como incendiada por dentro, muestra y revela hacia fuera, como llameada y en llamaradas, todo el misterio de las "Tres Personas una sustancia y un poder y un saber y un solo Dios”. La antropología se humaniza cuando la pneumatología actúa. Esto implica que cuando se le da cabida al Espíritu Santo en la vida del ser humano toda la persona se capacita para recibir la revelación del Dios de Jesús. Así el Espíritu Santo también posibilita que el mismo sea acogido por los sentidos corporales llenándolos de la verdad para descubrir y mostrar al Dios trino.

La inhabitación trinitaria constituye el proceso por el que el ser humano accede al misterio de comunión y entrega del Dios uno y trino. El ser humano es dichoso porque llega claramente al entendimiento y la comprensión de "lo que tenemos por fe". La vivencia teresiana es que el Padre, el Hijo y el Espíritu se revelan haciéndose comprensibles a la finitud humana ${ }^{30}$.

29 Cf. $7 \mathrm{M} \mathrm{1,6.} \mathrm{"se} \mathrm{le} \mathrm{muestra} \mathrm{la} \mathrm{Santísima} \mathrm{Trinidad,} \mathrm{todas} \mathrm{Tres} \mathrm{Personas,} \mathrm{con} \mathrm{una}$ inflamación que primero viene a su espíritu a manera de una nube de grandísima claridad, y estas Personas distintas, y por una noticia admirable que se da al alma, entiende con grandísima verdad ser todas Tres Personas una sustancia y un poder y un saber y un solo Dios".

30 Cf. 7M 1, 6. "de manera que lo que tenemos por fe, allí lo entiende el alma, podemos decir, por vista, aunque no es vista con los ojos del cuerpo ni del alma, porque no es visión imaginaria. Aquí se le comunican todas Tres Personas, y la hablan, y la dan a entender aquellas palabras que dice el Evangelio que dijo el Señor: que vendría El y el Padre y el Espíritu Santo a morar con el alma que le ama y guarda sus mandamientos (Jn 14, 23)". 
Teresa comunica en Cuentas de Conciencia 14 (29 de mayo 1571) la vivencia en que intervienen todos los sentidos, la vista, el oído, el gusto, el olfato y el tacto, para fortalecer las dimensiones teologales de la existencia cristiana. Así la fe enriquece la razón, la esperanza la ilumina y el amor lleva a plenitud el conocimiento. A través de los sentidos ${ }^{31}$, se percibe la realidad y el sujeto dialogante se inserta en el mundo cooperando a su plenificación. La conversión de Pablo se presenta como una caída de las escamas de los ojos, la comunión con Dios se expresa a través de la visión intelectual y de "una noticia admirable [...] con grandísima verdad". La simbología de la "Nube de grandísima claridad" es una antítesis porque normalmente la nube remite a una experiencia de noche y de obscuridad. Y acá se habla de un conocimiento certero de la trinidad.

En definitiva, el proceso explicado en V 17, $5^{32}$, ahora lo trasluce de otra manera. La comunicación da a entender el misterio que lleva a tomar conciencia de la experiencia de la inhabitación. Así, la comunicación es obra de las tres Personas de la Trinidad, la que se dona a Teresa para que entienda el misterio a través de la Palabra que le habla y la ayuda a concientizarse de lo que acontece como experiencia de Dios en ella. De otra manera, el proceso vivido y formulado lo ha experimentado en el seno de la Trinidad. Por lo cual el proyecto divino sobre la plena realización de lo humano y la garantía de no fracaso es que Dios inicia, acompaña y finaliza su obra y nos compromete a todos a seguir impulsándola con nuestra existencia en el mundo ${ }^{33}$. Es la perspectiva de la escatología donde nace

31 La vista cobra fuerza de modo más relevante, "las escamas de los ojos... la visión intelectual"; el oído cuando Teresa afirma que "dice el evangelio"; el gusto nace desde la Palabra proclamada y el ser humano la degusta; el olfato se estimula por "una noticia admirable... con grandísima verdad", el ser humano necesita olfatear la verdad; y el tacto se hace toque divino cuando Dios mora en cada ser.

32 V 17, 5: "Hay otra manera de unión, que aún no es entera unión, [...] porque una merced es dar el Señor la merced, y otra es entender qué merced es y qué gracia, otra es saber decirla y dar a entender cómo es".

33 Uniendo con el capítulo tercero que presentará el espanto ante la diversidad, ahora contemplamos la unidad, el proyecto de divinización para ser uno en todo como dice Ef 1, 10: "todo tenga a Cristo por cabeza". En el CIC 7 se dice: "Cristo es el Señor del cosmos (cf. Ef 4, 10; 1 Co 15, 24. 27-28) y de la historia. En Él, la historia de la humanidad e incluso toda la Creación encuentran su recapitulación (Ef $1,10)$, su cumplimiento transcendente".

Además, en la plenitud (Ga 4, 4: "Pero cuando vino el cumplimiento del tiempo, Dios envió a su Hijo, nacido de mujer y nacido bajo la ley") acontece la recapitulación por la cual Dios reunifica el mundo creado que el pecado ha disgregado 
la gran esperanza de toda la humanidad y su misterio con el fin de poder llegar a ser plenos y sabiendo que "dice el Evangelio que dijo el Señor: que vendría Él y el Padre y el Espíritu Santo a morar con el alma que le ama y guarda sus mandamientos (Jn 14, 23)"34.

\section{UNA ANTROPOLOGÍA LATENTE}

Se habla de antropología latente en el sentido de sacar a la luz lo que se encuentra implícito en el pensamiento teresiano. Si atendemos, en un segundo momento, a dos conceptos muy relevantes de la etapa mediana de la vida como son razón y amor, se divisa al ser humano con un camino ya recorrido y, a la vez, con la posibilidad de seguir mirando hacia la otra vertiente en dirección al futuro ${ }^{35}$.

La explicitación de la antropología teresiana pone de manifiesto que la creatura humana se va configurando con el Hijo hasta hacernos hijos de Dios, lo que salva dando sentido al misterio humano y otorga dirección y significado al espanto de la finitud. La perspectiva creacional presenta la dignificación de lo humano que, en torno a la mitad de la vida, es capaz de tomar conciencia del valor del amor al prójimo como el signo visible del amor a Dios aglutinante en el que todas las dimensiones humanas se unifican $(5 \mathrm{M} 3,9)$. La configuración desde la salvación descubre una persona realizándose gracias a la relación con los otros en libertad y creciendo en una mayor humanización. Desde dicha libertad es posible establecer relaciones a imagen de la comunidad trinitaria ( $4 \mathrm{M}$ $2,9)$. El ser humano avanza en un proceso de plena humanización a tra-

(Rm 8, 18-22: "Estoy seguro de que los sufrimientos por los que ahora pasamos no son nada, si los comparamos con la gloriosa vida que Dios nos dará junto a él. El mundo entero espera impaciente que Dios muestre a todos que nosotros somos sus hijos. Pues todo el mundo está confundido, y no por su culpa, sino porque Dios así lo decidió. Pero al mundo le queda todavía la esperanza de ser liberado de su destrucción. Tiene la esperanza de compartir la maravillosa libertad de los hijos de Dios. Nosotros sabemos que este mundo se queja y sufre de dolor, como cuando una mujer embarazada está a punto de dar a luz...").

$347 \mathrm{M} 1,6$.

35 Cf. A. Serrano, Una propuesta..., 253 p. Únicamente se revisan tres de los quince

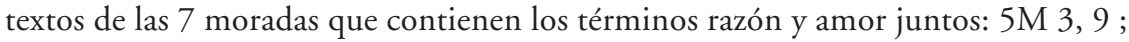
$4 \mathrm{M} \mathrm{2,} \mathrm{9;} \mathrm{y} 4 \mathrm{M} \mathrm{2,} \mathrm{8.} \mathrm{Los} \mathrm{textos} \mathrm{teresianos} \mathrm{en} \mathrm{las} \mathrm{tres} \mathrm{dimensiones} \mathrm{son:} \mathrm{de} \mathrm{creación:}$ 2M 1, 4; $5 \mathrm{M} \mathrm{3,} \mathrm{9;} \mathrm{6M} \mathrm{10,} \mathrm{4;} \mathrm{de} \mathrm{salvación:} \mathrm{3M} \mathrm{1,} \mathrm{7;} \mathrm{3M} \mathrm{2,} \mathrm{7;} \mathrm{3M} \mathrm{2,} \mathrm{8;} \mathrm{4M} \mathrm{2,} \mathrm{9;}$ $4 \mathrm{M} \mathrm{3,} \mathrm{4;} \mathrm{7M} \mathrm{4,} \mathrm{6;} \mathrm{y} \mathrm{de} \mathrm{la} \mathrm{dimensión} \mathrm{de} \mathrm{escatología:} \mathrm{4M} \mathrm{2,} \mathrm{8;} \mathrm{6M} \mathrm{1,} \mathrm{5;} \mathrm{6M} \mathrm{3,} \mathrm{6;}$ $6 \mathrm{M} \mathrm{7,11;7M} \mathrm{2,} 6$. 
vés de una interacción creativa de lo cognitivo y lo afectivo buscando la relación de amistad que dialoga con Dios (4M 2, 8). Desde el progreso en la presencia íntima con Dios, el ser se va divinizando y Teresa impulsa la apertura al compromiso de la unión plena con el Amado.

El ser humano dignificado por el amor y el conocimiento se va descubriendo como persona potenciada por la libertad finita de hijo que camina hacia la plenitud de la humanización ${ }^{36}$.

El hilo conductor se suministra desde los términos clave de 'razón' y 'amor' que aportan luz para rescatar de los textos teresianos una antropología unificada, relacional y comprometida desde una mirada de paso desde la ascética hacia la mística estudiada en las moradas intermedias (4-5M).

\subsection{La criatura dignificada por la razón y el amor}

La etapa intermedia entre la vida ascética y la mística es una especie de bisagra que pone en relación la vida vivida y la que está por vivirse. La aproximación creacional enfoca un ser humano enaltecido por la razón y el amor que es signo de una antropología unificada ${ }^{37}$.

La criatura puede ser entendida entonces como expresión del amor de Dios que, gracias a una progresiva compenetración de las diversas dimensiones de lo humano, va siendo capaz de perfección.

Para Teresa, el amor al prójimo es el signo visible del amor a Dios, el que se manifiesta en la cotidianeidad de los hechos concretos y desde la humildad sin pretensiones engañosas. La antropología latente teresiana remite a la posibilidad de una creación surgida del amor gratuito de Dios ("de la nada") para plenificarse en ese amor a través de una historia salvífica. Aunque lo creado tiene una propensión al mal, también es capaz de transformación.

De este modo, el amor a la criatura es posible si la persona nace desde la hondura del amor de Dios, donde se descubre la dignidad humana. Se invita así a medir el amor hacia Dios desde el amor al prójimo ${ }^{38}$.

36 Cf. A, Serrano, Una propuesta..., 66 nota 102; 135-137; y 184-186. Cf. P. Moya, El conocimiento: nuestro acceso al mundo. Cinco estudios sobre filosofía del conocimiento (Editorial Universitaria, Santiago de Chile 2013, 198 p.).

37 Cf. $5 \mathrm{M} \mathrm{3,9.}$

38 Cf. 5M 3, 9. "Impórtanos mucho andar con gran advertencia cómo andamos en esto; que, si es con mucha perfección, todo lo tenemos hecho; porque creo yo que 
Para ello plantea la necesidad de prestar atención a nuestra relación con el otro "andar con gran advertencia cómo andamos en esto". Además, se insta a la toma de conciencia de la propia finitud y de la propensión al mal instalado en el ser humano, "según es malo nuestro natural". También se requiere una conversión fundamental desde de lo profundamente humano, para que la existencia sea vivida en clave de amor. Dice Teresa "naciendo de raíz del amor de Dios, [...] llegaremos a tener con perfección el del prójimo”.

La unión entre acción y contemplación posibilita la aplicación a la vida cotidiana de lo descubierto en la oración. De esa manera se va consiguiendo la dignificación de la criatura gracias al incremento del amor y el conocimiento, gracias al desarrollo de una racionalidad amorosa ${ }^{39}$.

Se trata de hacer dialogar el entender y el amar en todo lo que conduce al ennoblecimiento de la criatura. Para ello se requiere la atención y el cuidado de lo pequeño y la no pretensión de grandezas irrealizables.

La tarea del discernimiento en el amor y en el conocimiento va desenmascarando el engaño y posibilita una existencia en la humildad, donde es posible vivir alejados de pretensiones soberbias que atan a la esclavitud del éxito ${ }^{40}$.

Como dice la abulense, andando en verdad descubriremos el daño que causa la mentira y será posible y razonable la apertura a la libertad como signo de que el ser humano puede nacer a "estas virtudes [...] que da Dios", para amar sin fingimiento al otro sabiendo sobre la dignidad de ser imagen y semejanza de Dios.

según es malo nuestro natural, que si no es naciendo de raíz del amor de Dios, que no llegaremos a tener con perfección el del prójimo".

39 Cf. 5M 3, 9. "Pues tanto nos importa esto, hermanas, procuremos irnos entendiendo en cosas aun menudas y no haciendo caso de unas muy grandes, que así por junto vienen en la oración, de parecer que haremos y aconteceremos por los prójimos y por sola un alma que se salve; porque, si no vienen después conformes las obras, no hay para qué creer que lo haremos".

40 Cf. 5M 3, 9. "Así digo de la humildad también y de todas las virtudes; son grandes los ardides del demonio, que por hacernos entender que tenemos una, no la teniendo, dará mil vueltas al infierno; y tiene razón, porque es muy dañoso, que nunca estas virtudes fingidas vienen sin alguna vanagloria, como son de tal raíz, así como las que da Dios están libres de ella ni de soberbia”. 


\subsection{La persona potenciada por la libertad de hijo}

En la medianía de la vida, la cuarta morada leída en clave soteriológica, se propone el desarrollo humano mediante la interacción dialogante de la libertad de Dios y la libertad del ser humano. El texto teresiano permite atisbar una antropología relacional, en cuanto que amor y conocimiento dan cuenta del sujeto como apertura y búsqueda de otro ${ }^{41}$.

El ser humano logra y alcanza mayores cotas de humanidad en la referencia a Dios, así la gracia regala la salvación y la persona se capacita para transcenderse pudiendo llegar a su realización más plena.

La libertad de Dios que conoce al ser humano se ofrece como fundamento de la misma libertad humana cuando la persona libremente reconoce su creaturalidad y finitud, acogiendo la gracia como regalo inmerecido. Teresa otorga una serie de razones para propiciar un proceso hacia una vida en plenitud gracias al seguimiento de Jesús que conduzca a superar el cumplimiento apostando por un bien mayor: el amor gratuito. La subyacente antropología teresiana se devela rebasando la condición creatural hacia un proceso de salvación por la gracia de Dios. La absoluta gratuidad de Dios es la razón última para lanzarse al servicio del "crucificado" imitando su amor desinteresado.

Dios en su libertad conoce a su creatura y desea que cumpla sus deseos más profundos; un Dios que nos ama como hijos y que "se deja vencer" por la humildad ${ }^{42}$.

El ser humano consciente de su libertad finita no reclama a Dios ni pretende merecer la gracia; no se cree con derecho sino que acoge su don. La invitación teresiana a la receptividad implica una actitud liberadora ${ }^{43}$.

Ella expone cinco razones para la recepción de los dones libre de pretensiones. Es decir, acoger la gracia gratuita sin merecimiento. Sus tres primeras razones se agrupan en torno al amor gratuito hacia Dios

$41 \quad$ Cf. $4 \mathrm{M} \mathrm{2,} 9$.

42 Cf. $4 \mathrm{M}$ 2, 9. "Yo os diré lo que en esto he entendido: dejemos cuando el Señor es servido de hacerla porque su Majestad quiere y no por más. Él sabe el porqué; no nos hemos de meter en eso. Después de hacer lo que los de las moradas pasadas: ¡humildad, humildad!; por ésta se deja vencer el Señor a cuanto de él queramos".

43 Cf. 4M 2, 9. "Y lo primero en que veréis si la tenéis es en no pensar que merecéis estas mercedes y gustos del Señor ni los habéis de tener en vuestra vida. Diréisme que de esta manera que cómo se han de alcanzar no los procurando". 
unido con la humildad servicial del ser humano, aspectos que acompañan un seguimiento radical. La cuarta y la quinta razón defienden que la libertad finita es sostenida por la libertad de Dios generando un diálogo fructífero fundado en su gratuidad absoluta ${ }^{44}$. Dios no está forzado al trueque humano del yo te doy y del tú me das. Él sabe quien le ama y conoce lo que más conviene para cada uno. Entonces, cuando el ser humano descubre a este Dios puede vivir su existencia por "el camino del amor [... sirviendo] a su Cristo crucificado" y puede, incluso, renunciar a pequeños gustos y parcelas de libertad. El ser humano se compromete al amor y al servicio y, además por añadidura, a la renuncia, "no solo no le piden gustos ni los desean, mas le suplican no se los dé”.

\subsection{El ser humano divinizándose por la gracia}

La razón y el amor remiten a dimensiones de la existencia humana que concurren para una mayor humanización. La perspectiva escatológica descubre un Dios que sostiene su proyecto salvífico con la cooperación humana, lo que revela una antropología comprometida ${ }^{45}$.

El ser humano alcanza su plenificación a través de un proceso de divinización, regalado en la colaboración con Dios mediante la gracia sobreabundante que garantiza el cumplimiento del plan divino.

La experiencia inicial de unión con Dios se verifica en la vida concreta. La persona consciente de los dones recibidos percibe la gracia sobre-

44 Cf. 4M 2, 9. "A esto respondo que no hay otra mejor de la que os he dicho y no los procurar, por estas razones: la primera, porque lo primero que para esto es menester es amar a Dios sin interés; la segunda, porque es un poco de poca humildad pensar que por nuestros servicios miserables se ha de alcanzar cosa tan grande; la tercera, porque el verdadero aparejo para esto es deseo de padecer y de imitar al Señor, y no gustos, los que, en fin, le hemos ofendido; la cuarta, porque no está obligado su Majestad a dárnoslos como a darnos la gloria, si guardamos sus mandamientos; que sin esto nos podremos salvar, y sabe mejor que nosotros lo que nos conviene y quién le ama de verdad; y así es cosa cierta, yo lo sé, y conozco personas que van por el camino del amor, como han de ir, por solo servir a su Cristo crucificado, que no solo no le piden gustos ni los desean, mas le suplican no se los dé en esta vida. Esto es verdad. La quinta es porque trabajaremos en balde, que, como no se ha de traer esta agua por arcaduces, como la pasada, si el manantial no la quiere producir, poco aprovecha que nos cansemos; quiero decir que, aunque más meditación tengamos y aunque más nos estrujemos y tengamos lágrimas, no viene este agua por aquí; solo se da a quien Dios quiere y cuando más descuidada está muchas veces el alma”.

45 Cf. 4M 2, 8. 
abundante que la impulsa hacia una vida implicada en el seguimiento sin retorno. El compromiso se nutre en la relación de amistad con Dios donde todo el ser humano -razón y amor- se arriesga y empeña en alcanzar la unión. La antropología teresiana, desde la escatología, revela el protagonismo de Dios y conduce a la unión donde se atisba un rebasamiento del umbral ontológico que lleva a la consumación.

El compromiso es un signo expresivo de la oración que se refleja en la práctica. La voluntad del ser humano unida a la voluntad de Dios progresa en conciencia de la gracia recibida inmerecidamente que se patentiza en las obras, lugar de la purificación de la relación con Dios. Teresa invita a que cada persona se implique tratando de que todo lo creado y salvado llegue a buen término ${ }^{46}$.

El ser humano al tomar conciencia descubre la gran gracia recibida inmerecidamente que ayuda en el avance sin tornar atrás hasta la plena humanización. El ser humano que se hace consciente de ser regalado vive una mayor gracia, una sobreabundancia de gracia, experimenta la gracia sobreabundante. El hacerse consciente de la gracia supone un incremento de ella "harto gran merced es de nuestro Señor". La imagen del crisol que purifica, y la imagen de la carrera, en la que no se torna atrás, evoca a Pablo llegando a la meta del encuentro con el Señor (CV 21, 2).

El autoconocimiento se recibe desde la aproximación a Dios en la interioridad donde se devela el misterio del ser humano como compenetración de razón y amor, y se devela el misterio de Dios mediante la unión para la divinización "saber cómo alcanzaremos esta merced" 47 .

El ser humano con razón y deseo procura la oración, relación de amistad dialogante con quien ama, porque en Teresa se va develando el propio enigma; aquellos "secretos que me traen espantada" (4M 2, 5) para poder "acaba[r] de entender el alma". Lo que se recibe gratuitamente mediante la unión para la divinización. El ser humano con razón

46 Cf. 4M 2, 8. "La voluntad bien me parece que debe estar unida en alguna manera con la de Dios, mas en los efectos y obras de después se conocen estas verdades de oración, que no hay mejor crisol para probarse. Harto gran merced es de nuestro Señor si la conoce quien la recibe y muy grande si no torna atrás".

$474 \mathrm{M} \mathrm{2,8.} \mathrm{"Luego} \mathrm{querréis,} \mathrm{mis} \mathrm{hijas,} \mathrm{procurar} \mathrm{tener} \mathrm{esta} \mathrm{oración} \mathrm{y} \mathrm{tenéis} \mathrm{razón,} \mathrm{que,}$ como he dicho, no acaba de entender el alma las que allí la hace el Señor y con el amor que la va acercando más a sí; que cierto está desear saber cómo alcanzaremos esta merced". 
y amor se encamina hacia la divinización. El deseo de saber es ya obra de la gracia actuando en nosotros que nos hace ser creativos a la hora de poner los medios adecuados para alcanzar el regalo de la unión. Aún estamos en la mitad del camino, cuarta morada, etapa de grandes opciones de definitividad que nos aproximan a la dimensión dialógica del misterio; que nos enfrentan al espanto de la finitud; y que nos sitúan ante una antropología comprometida por lograr la plenitud ${ }^{48}$.

\section{EL ENIGMA DE LA FINITUD}

La palabra teresiana 'espanto' abre una clave de acceso a los grandes temas antropológicos que subyacen al pensamiento de la escritora. De esta manera, un estudio de la expresión 'espanto' en las primeras moradas, presenta la finitud experimentada en la historia y se interpreta desde la creación, la salvación y la consumación. Así, se establece la etapa inicial del proceso en la que el esfuerzo humano es más notable. Es un tiempo de combate y lucha, de ascesis en la que el ser humano se va armando paradójicamente a través del despojamiento y la desnudez ${ }^{49}$.

En el primer periodo existencial, el espanto acampa sin restricciones y se va iluminando desde la escatología. Mientras se busca la unidad, la diversidad va conduciendo hacia el asombro y el sobrecogimiento en que la criatura puede transitar sin espantarse (3M 2, 13). En el camino, el ser humano descubre como fuerza que pasma y desafía al poder del mal porque afecta a cada persona y a su relacionalidad con lo todo existente, en especial con los otros y con Dios (1M 2, 5). De todos modos, el misterio humano es visto desde la plenitud y la autora transmite su experiencia de definitividad con el Amado. Esto se da como un encuentro experimentado a través de una presencia gratuita y liberadora que plenifica. Dicho con lenguaje simbólico, la autora expresa su vivencia del estupor y del pavor hablando de manantial, perfume y metal precioso $(4 \mathrm{M} 2,6)$.

48 A. BriñAs, "Cuartas Moradas: del desconcierto a la confianza", en Revista Teresa de Jesús 183 (2013) 23-25. Cf. A. SERrAnO, "Educación para la gratuidad mediante la experiencia”, en F. PARra - A. Serrano (Ed.) La inteligencia de la esperanza, Anales de la Facultad de Teología 5 (2012) 339-365.

49 Cf. A. Serrano, Una propuesta... 253 p. Únicamente se estudian tres textos con el

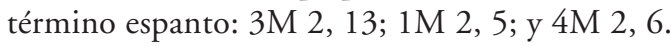


El asombro y el sobrecogimiento; la admiración y el desafío; el estupor y el pavor, son vocablos que expresan el espanto teresiano y remiten a un misterio tremendo y fascinante. Dicho espanto surge ante la diversidad y permanece ante la alteridad, para finalmente desvanecerse ante la definitividad donde acontece el develamiento del misterio. El ser humano que camina hacia la plenificación experimenta el misterio de esas diversas y enriquecedoras maneras ${ }^{50}$.

El hilo conductor se establece siguiendo el término clave de espanto desde el cual se descubre en Teresa una antropología dialógica, inclusiva e integral desde el comienzo del proceso, es la etapa de la ascética abordada en las moradas iniciales (1-4M).

\subsection{El espanto ante la diversidad}

El misterio de la finitud de lo creado provoca asombro y sobrecogimiento ante la posibilidad de la unidad buscada en la diversidad, lo que remite a una antropología dialógica ${ }^{51}$.

Así, se presenta la obra creada como riqueza plural para ser acogida por la creatura desde el silencio contemplativo y la esperanza. De modo que la aceptación del otro con su especificidad conduce a la criatura hacia la apertura a lo nuevo del futuro. La antropología latente teresiana invita a apoyar la creatividad de cada persona sin prescripciones ni coacciones. El Dios creativo estimula la diversidad en su obra creadora para que el ser humano valore y potencie la creatividad humana sin "espantarse".

El texto teresiano pretende un aprendizaje de lo bueno de los otros sin imponer la propia ignorancia. Para ello se necesita un proceso de interiorización que incorpore la realidad en el proceso vocacional ${ }^{52}$.

50 Cf. A. Serrano, Una propuesta... 68-70; 138-140; y 188-190. Cf. T. Álvarez, Diccionario de Santa Teresa de Jesús (Monte Carmelo, Burgos 2000, 1464 p.). Cf. C. Holzapfel, De cara al limite (Ediciones metales pesados, Santiago de Chile 2012, 199 p.).

51 Cf. 3M 2, 13.

52 Cf. 3M 2, 13. "Miremos nuestras faltas y dejemos las ajenas, que es mucho de personas tan concertadas espantarse de todo y por ventura de quien nos espantamos podríamos bien deprender en lo principal, y en la compostura exterior y en su manera de trato le hacemos ventajas; y no es esto lo de más importancia, aunque es bueno, ni hay para qué querer luego que todos vayan por nuestro camino, ni ponerse a enseñar el del espíritu quien por ventura no sabe qué cosa es”. 
La contemplación, la profundización y la aceptación de la diversidad son medios teresianos imprescindibles para una adecuada formación en todo proceso educativo. Los vocablos "bien, bueno, mejor" indican una valoración positiva de la creación cuyo origen (el porqué) y cuya meta (el para qué) es el amor divino, que sostiene todo lo existente. Reconocer la propia finitud libera de creernos poseedores únicos del "espíritu" y dominadores de la verdad, obligados a "querer luego que todos vayan por nuestro camino".

La autora suplica la acción permanente de Dios para evitar que el ser humano se valga exclusivamente de las propias maneras porque en ocasiones buscando "el bien de las almas, podemos hacer muchos yerros y así es mejor llegarnos a lo que dice nuestra Regla: en silencio y esperanza procurar vivir siempre, que el Señor tendrá cuidado de sus almas" 53 .

Dios cuida la creación mediante su creatividad que es el soporte de la originalidad humana, lo que posibilita a la criatura la apertura a la llamada divina. Así lo formula la "Regla" carmelitana cuando citando un texto de Isaías, invita a la interioridad y la esperanza confiada. El camino de la conversión y la calma, del sosiego y la seguridad, de la quietud y la confianza; vías que posibilitan una respuesta fiel a la vocación recibida, "en silencio y esperanza será vuestra fortaleza" ${ }^{4}$.

\subsection{El espanto ante la relacionalidad}

El enigma de la finitud salvada provoca admiración y desafío ante la capacidad de relacionalidad como alteridad dialogante entre Dios y el ser humano. Esto permite hablar de una antropología inclusiva ${ }^{55}$. Puesto que la persona a la vez que queda espantada al tomar conciencia del gran

53 Cf. 3M 2, 3. "que con estos deseos que nos da Dios, hermanas, del bien de las almas, podemos hacer muchos yerros y así es mejor llegarnos a lo que dice nuestra Regla: en silencio y esperanza procurar vivir siempre, que el Señor tendrá cuidado de sus almas; como no nos descuidemos nosotras en suplicarlo a su Majestad, haremos harto provecho con su favor. ¡Sea por siempre bendito!”.

54 J.V. Rodríguez, Castillo Interior..., 61. José Vicente Rodríguez en la nota 14 de la página 61 afirma que la Regla carmelitana es "en silencio y esperanza será vuestra fortaleza" basada en el texto de Isaías 30, 15: "Porque así dice el Señor, Yahveh, el Santo de Israel: «Por la conversión y calma seréis liberados, en el sosiego y seguridad estará vuestra fuerza» Pero no aceptasteis" (Biblia de Jerusalén 1977).

55 Cf. $1 \mathrm{M} \mathrm{2,5.}$ 
poder del pecado, también recibe la gracia de conocer la propia verdad, y puede abrirse a la súplica y la alabanza de Dios.

La experiencia de otros también ayuda a la autora en el afrontamiento del tema del pecado mortal y para estimular la toma de conciencia que evite la caída. Lo que es posible desde un proceso de autoconocimiento y junto con la gracia de Dios que alimenta como "fuente y sol". La antropología implícita revela la singularidad de lo humano que se pone de manifiesto en las relaciones interhumanas. La relacionalidad revela que lo personal repercute a nivel social.

En el segundo capítulo de la primera morada, tras la mostración de la gran dignidad humana, se aborda el poder del pecado. El ser humano se espanta, se siente desafiado y se pasma de la amplitud y extensión del mal, lo que permite que se abra a la relación ${ }^{56}$.

Teresa en diálogo con expertos de su tiempo, "Oí una vez a un hombre espiritual”, descubre al profundizar que la gravedad del pecado consiste en el mal realizado, pero sobre todo en el bien que no se construye: "no se espantaba de cosas que hiciese uno que está en pecado mortal, sino de lo que no hacía”. La mayor amenaza consiste en ir dejando el campo libre al dominio del "pecado mortal" que fomenta el desarrollo del mal. Ante lo cual surge en Teresa la petición a Dios junto con el empeño personal por impedir los "males eternos para sin fin". La persona puede oponerse a la fuerza centrífuga de división y, "Dios por su misericordia nos libre”, con la gracia encaminarse hacia el centro del castillo donde se reconoce a sí misma amada y liberada en el encuentro con Dios junto con todo lo creado.

La toma de conciencia de la fuerza del pecado junto con la incapacidad para acabar con la injusticia, se expresa recordando que la persona necesita la gracia para una adecuada respuesta vocacional ${ }^{57}$.

56 Cf. $1 \mathrm{M} 2$ 2, 5. "Oí una vez a un hombre espiritual que no se espantaba de cosas que hiciese uno que está en pecado mortal, sino de lo que no hacía. ¡Dios por su misericordia nos libre de tan gran mal, que no hay cosa mientras vivimos que merezca este nombre de mal sino ésta, pues acarrea males eternos para sin fin!”.

57 Cf. 1M 2, 5. "Esto es, hijas, de lo que hemos de andar temerosas y lo que hemos de pedir a Dios en nuestras oraciones, porque si él no guarda la ciudad en vano trabajaremos, pues somos la misma vanidad. Decía aquella persona que había sacado dos cosas de la merced que Dios le hizo: la una, un temor grandísimo de ofenderle y así siempre le andaba suplicando no la dejase caer viendo tan terribles daños". 
La relación salvadora de Dios con el ser humano evita el engreimiento y descubre la fragilidad y la propensión al mal, porque "si él no guarda la ciudad en vano trabajaremos" (Sal 126, 2), y sigue diciendo Teresa por eso "hemos de andar temerosas y [... con] un temor grandísimo de ofenderle". Gracias a la relacionalidad como alteridad es posible que el ser humano pida -en el diálogo oracional- la gracia para no sucumbir al pecado y la fuerza para una existencia vigilante y en alerta "suplicando no la dejase caer". La relación con Dios se traduce en la escucha de la invitación a entrar al castillo, en la primera morada, dejando atrás todo el mal y renunciando a todo lo que implique un retroceso. La alteridad divina experimentada y vivida como relación amorosa en la oración de súplica provoca el reconocimiento de la indigencia, de que el ser humano es menesteroso y necesitado de la gracia divina para acometer la conflictividad de los "tan terribles daños".

La gracia como signo de la alteridad entre Dios y el ser humano es "un espejo para la humildad", porque ayuda al autoconocimiento y a la alabanza de Dios; es decir, la persona reconoce su finitud ante la infinitud divina y agradece la salvación ${ }^{58}$.

La experiencia de la incapacidad humana abre a la gracia de Dios que posibilita el autoconocimiento de sí junto con la gratitud a Dios. La autora, a través de un lenguaje simbólico, habla de un ser humano deseoso de conocimiento y necesitado de alteridad: la imagen de un árbol que se alimenta de la tierra buena porque es regada por la "fuente" de vida, un árbol que crece iluminado por el "sol". El ser humano que conoce a Dios, bebe en su "fuente", genera frutos: "nuestras obras", que el mismo Dios va haciendo crecer y madurar con el "calor" de su amor. Se presenta una antropología inclusiva de los deseos más profundos del ser humano; deseo de conocimiento y del amor. La persona humilde que se cimenta en valores evangélicos descubre que toda "cosa buena que hagamos" es don de Dios, es regalo y consecuencia de una existencia sostenida en la gracia porque "sin esta ayuda no podíamos nada". El reconocimiento

58 Cf. $1 \mathrm{M} 2$ 2, 5. "la segunda, un espejo para la humildad, mirando cómo cosa buena que hagamos no viene su principio de nosotros, sino de esta fuente adonde está plantado este árbol de nuestras almas, y de este sol que da calor a nuestras obras. Dice que se le representó esto tan claro que, en haciendo alguna cosa buena o viéndola hacer, acudía a su principio y entendía cómo sin esta ayuda no podíamos nada; y de aquí le procedía ir luego a alabar a Dios y, lo más ordinario, no se acordaba de sí en cosa buena que hiciese". 
de nuestro ser creatura alimentada por la gracia divina capacita para la salvación que consiste en la lucha contra el mal, el "pecado mortal"; y la apuesta por el bien, lo que encamina hacia la gratuidad que desemboca en la alabanza. Al centrarse en la acción de Dios, se cambia la mirada y el ser humano renuncia al egoísmo "no se acordaba de sí en cosa buena que hiciese". El conocimiento de la propia finitud lejos del engreimiento fija la mirada en el donante, en el Creador Salvador que genera una creatura finita y perfectible. Así la oración de petición y de alabanza configuran una interioridad capaz de interrelacionalidad que salva acogiendo la propia finitud y estableciendo relaciones liberadoras que posibilitan encuentros gratuitos, basados en la humildad y el altruismo que únicamente el Amor de Dios fundamenta y fecunda.

\subsection{El espanto ante la definitividad}

Una tercera dimensión trabaja el enigmático misterio de la finitud en proceso hacia la plenificación. El enigma humano provoca un espanto ante la definitividad que asumiendo con estupor y pavor la realidad humana se abre a una antropología integral ${ }^{59}$.

El ser humano en unidad -cuerpo y alma-, recibe la gracia y se encamina al encuentro con el Amado donde experimenta el temblor y el temor.

La presencia de Dios afecta a todo el ser humano y el misterio divino "embebe" todas las dimensiones del ser. La escatología teresiana se manifiesta a través de una subyacente antropología que da cuenta de la gratuidad divina trayendo al presente el futuro de la plenitud. Además, la transcendencia encarnada en la inmanencia, Teresa la explica a través de imágenes que acercan al "ya sî" de la definitividad.

La autodonación de Dios al ser humano se comunica a través del símbolo del agua y del perfume. La gracia divina se convierte en torrente que desborda y en aroma que "penetra toda el alma, y [...] participa el cuerpo" ${ }^{60}$.

\section{Cf. 4M 2, 6.}

60 Cf. $4 \mathrm{M} \mathrm{2,} \mathrm{6.} \mathrm{"Tornando} \mathrm{al} \mathrm{verso} \mathrm{en} \mathrm{lo} \mathrm{que} \mathrm{me} \mathrm{puede} \mathrm{aprovechar,} \mathrm{a} \mathrm{mi} \mathrm{parecer,} \mathrm{para}$ aquí es en aquel ensanchamiento, que así parece; que, como comienza a producir aquella agua celestial de este manantial que digo de lo profundo de nosotros, parece que se va dilatando y ensanchando todo nuestro interior y produciendo unos bienes que no se pueden decir, ni aun el alma sabe entender qué es lo que se le da allí: entiende una fragancia, digamos ahora, como si en aquel hondón interior estuviese 
La manifestación de Dios a la criatura salvada hacia la plenitud genera un espacio para la acogida que va siendo llenado hasta su rebasamiento, lo que provoca un torrente que brota desde dentro, un "ensanchamiento [...que] comienza a producir aquella agua celestial de este manantial". A la imagen de la catarata de agua que inunda, le sigue la de aroma que impregna todo el ser, y devela la delicada acción de Dios en la persona, "bienes que no se pueden decir, ni aun el alma sabe entender qué es lo que se le da allí: entiende una fragancia, [...] un brasero adonde se echasen olorosos perfumes". Una vez más se habla de la integralidad y la unidad de la antropología teresiana que se sirve de imágenes como el "calor y el humo oloroso" para expresar de manera sencilla, que Dios se deja ver, sentir, oler, y también gustar y tocar por el ser humano.

Pasa de las imágenes a la explicación racional de esta percepción de la gratuidad divina. Es una experiencia rebasadora de los sentidos que requiere ser comunicada, a través del diálogo, y para que vaya plenificando al ser humano ${ }^{61}$.

En primer lugar, se trata de una experiencia de la plenitud que supera los sentidos corporales, "ni se siente calor ni se huele olor, que más delicada cosa es que estas cosas". En segundo lugar, Teresa habla de lo que el ser humano descubre como verdad y aunque es inefable trata de comunicarlo a través de imágenes, comparaciones, metáforas, todo lo que el lenguaje pone a su disposición con la única pretensión de "dároslo a entender y entiendan las que no han pasado por esto, que es verdad que pasa así y que se entiende y lo entiende el alma más claro que yo lo digo ahora”. En tercer lugar se aborda la gracia como un regalo inmerecido como el más preciado don divino que plenifica el deseo más profundo de lo humano, "no es esto cosa que se puede antojar, porque por diligencias que hagamos no lo podemos adquirir, y en ello mismo se ve no ser de nuestro metal, sino de aquel purísimo oro de la sabiduría divina”.

un brasero adonde se echasen olorosos perfumes; ni se ve la lumbre ni dónde está; mas el calor y humo oloroso penetra toda el alma, y aun hartas veces, como he dicho, participa el cuerpo".

61 Cf. 4M 2, 6. "Mirad, entendedme, que ni se siente calor ni se huele olor, que más delicada cosa es que estas cosas, sino para dároslo a entender y entiendan las personas que no han pasado por esto, que es verdad que pasa así y que se entiende y lo entiende el alma más claro que yo lo digo ahora; que no es esto cosa que se puede antojar, porque por diligencias que hagamos no lo podemos adquirir, y en ello mismo se ve no ser de nuestro metal, sino de aquel purísimo oro de la sabiduría divina”. 
De este modo, se vivencia la salvación mediante atisbos de la plenitud futura en el presente, se experimenta que todo el ser humano está habitado y va siendo llenado "de la sabiduría divina"62.

La inhabitación provoca que la memoria, el entendimiento y la voluntad queden "embebidas", como "espantadas" y fascinadas, seducidas y sobresaltadas. En definitiva, el espanto del ser humano ante la definitividad que propone la esperanza, consiste en la vivencia de un Dios como gratuidad que lleva a plenitud su proyecto amoroso.

En síntesis, el espanto ante la diversidad, la relacionalidad y la definitividad que devela la esperanza; asombra y sobrecoge; admira y desafía; causa temblor y temor; para ir develando una antropología dialógica, inclusiva e integral.

Teresa comienza invitando a "entrar" al castillo para conocerse conociendo a Dios, "jamás nos acabamos de conocer, si no procuramos conocer a Dios" (1M 2, 9) y termina la obra explicando que la salida es para "que nazcan siempre obras, obras" (7M 4, 6). Las primeras palabras son: "Pocas cosas que me ha mandado la obediencia se me han hecho tan dificultosas como escribir ahora" (M Pról 1) y termina diciendo: "Aunque cuando comencé a escribir esto que aquí va fue con la contradicción que al principio digo, después de acabado me ha dado mucho contento, y doy por bien empleado el trabajo, aunque confieso que ha sido harto poco" (M Epilg 1).

\section{A MODO DE CONCLUSIÓN}

Con el fin de recapitular, se puede afirmar que este estudio presenta un atrevido intento de sintetizar la antropología teresiana desde algunos textos relevantes y significativos de su obra el Castillo Interior. Asimismo, se ha pretendido mostrar de un modo breve, denso y profundo la infinitud que habita lo humano para renovar la conciencia en que del misterio divino y humano "sabemos tanto como nonada"63.

La latente antropología teresiana se puede comprender como el misterio del ser humano que va develándose gracias al Espíritu Santo. En

$624 \mathrm{M} \mathrm{2,} \mathrm{6.} \mathrm{"sino} \mathrm{de} \mathrm{aquel} \mathrm{purísimo} \mathrm{oro} \mathrm{de} \mathrm{la} \mathrm{sabiduría} \mathrm{divina.} \mathrm{Aquí} \mathrm{no} \mathrm{están} \mathrm{las} \mathrm{po-}$ tencias unidas, a mi parecer, sino embebidas y mirando, como espantadas, qué es aquello".

$634 \mathrm{M} \mathrm{2,5.}$ 
primer lugar, las notas de evolutiva, personalista y esperanzada concentran la antropología teológica subyacente en el Castillo Interior desde la dimensión transcendente del ser humano habilitada por el Espíritu, el cual opera en cada persona creada a imagen y semejanza de Dios. Además, el Espíritu humaniza en la encarnación y plenifica hacia la resurrección en una comunidad eclesial presente en el mundo y su historia ${ }^{64}$.

Desde una pneumatología que humaniza se puede calificar a la antropología teresiana como de evolutiva cuando nos concentramos en un ser humano que progresivamente, con altos y bajos, avances y retrocesos, va integrando las diversas dimensiones de lo humano. Gracias al Espíritu de Dios, el ser humano puede ir evolucionando hacia la configuración con Cristo desde su ser creado a imagen y semejanza de Dios.

La valoración de personalista a la antropología teresiana desde su pneumatología humanizadora es debido a la profunda y comprometida relación dialogal que se establece entre el ser humano y Jesucristo hasta hacerse uno con Él (1Cor 6, 17). Se llega a decir que la muerte es la máxima ganancia ("lucrum") porque esta unión tan profunda con el Espíritu del Señor hace experimentar las cotas más altas de humanización que se regalan ya en la encarnación.

La caracterización de la antropología pneumatológica teresiana como esperanzada es posible desde una clave escatológica. Desde la luz de la resurrección se interpreta que el origen y la historia también están sustentados en Dios y van caminando a su cumplimiento. Gracias al Espíritu Santo la iniciativa y la resolución están garantizadas en la fidelidad de Dios que en diálogo con el ser humano le hace partícipe y colaborador en el plan soteriológico de toda la creación hacia la plenificación.

Podemos sentirnos llamados a ser solidarios en la búsqueda inteligente de la fe poniendo en diálogo todas las dimensiones humanas que dignifican al ser humano creado, salvado y plenificado para entender la transcendencia en la inmanencia, para en definitiva, ser mediación que transparenta el Amor de Dios Uno y Trino.

La segunda terna de rasgos describe la antropología teresiana en torno a la mitad de la vida como unitaria, relacional y comprometida. Esto se da cuando esta antropología trata de explicar al ser humano desde la

${ }^{64}$ Cf. A. Serrano, "Antropología teológica latente en el Castillo Interior de Santa Teresa de Jesús”, en Revista Teresianum 63 (2012) 191-211. 
compenetración del amor y la razón: lo que descubre un ser dignificado, potenciado por la libertad y divinizándose por gracia.

La antropología teresiana es unitaria gracias a su concepción de ser humano. Esta visión lo sitúa como un ser creatural que se va procesualmente realizando con una compenetración en diálogo del amor y de la razón hasta llegar a la plena humanización gracias a una historia de salvación. Así, el ser humano está llamado a descubrirse como un ser dignificado que sabiendo de su propensión al mal es capaz de amar al estilo como Dios ama.

Otra característica de esta antropología es la relacionalidad debido a su perspectiva soteriológica en que la libertad de Dios y la libertad humana dialogan interactuando con el fin de conseguir una posible compenetración del amor y la razón; lo que se pone de manifiesto a través de un ser humano capaz de búsqueda y de apertura a lo otro. Un sujeto que crece en referencia a la transcendencia y va siendo potenciado por la libertad de Jesucristo que muestra el valor del amor gratuito y desinteresado, lo que atrae hacia el seguimiento del crucificado que ha sido resucitado.

La tercera característica de la latente antropología es ser comprometida lo que emana de la perspectiva escatológica teresiana que contempla lo humano desde el final que ilumina la relación de amistad y diálogo con Dios gracias a la compenetración del amor y la razón. Un compromiso que, por parte de Dios, es fiel -no falla nunca-y regala la gracia para poder vivir el seguimiento hasta el final. De tal modo que el ser humano consciente del don recibido avanza y se plenifica, divinizándose por gracia.

Por lo tanto, podemos sentirnos participantes en la idea teresiana de que la mística dialoga con la teología, ya que mutuamente se requieren para historizar lo eterno y expresar la Buena Nueva de Jesucristo: que se encarna; que vive un estilo de vida anunciando el reinado de Dios; que muere y resucita cumpliendo la voluntad del plan salvador de Dios.

Finalmente, gracias al Espíritu Santo, la antropología teológica teresiana se puede caracterizar de dialógica, inclusiva e integral, cuando revelan al ser humano desde la clave del misterio que Teresa expresa con su vocablo 'espanto': que se manifiesta ante la diversidad, la alteridad y la definitividad.

Explicitando más se puede decir que Teresa propone el diálogo como disposición y talante ante el espanto que asombra y sobrecoge al ser 
humano frente a la multiplicidad plurivalente. Diversidad generada por la obra divina creada; diversidad constatada cuando se da la aceptación de lo otro; y, también diversa, la creatividad humana signo y reflejo del Dios creador y creativo.

Otra disposición y práctica teresiana es la capacidad de inclusión que puede acoger los deseos más profundos de la persona luchando contra el mal y a favor del bien. Así el diálogo inclusivo remite a la alteridad renunciando al egoísmo, lo que provoca admiración y desafío, es decir, “espanto" en palabras de Teresa.

Y la tercera nota del estilo teresiano es la intregalidad ante el espanto -estupor y pavor- que genera la definitividad, en un contexto en que prima lo pasajero y provisional. Definitividad que el ser humano puede descubrir como signo de la gratuidad divina que rebasa lo humano y que se deja sentir en el diálogo amoroso contemplativo.

Entonces, podemos sentirnos invitados por la abulense al diálogo entre teología y mística que remite a relacionar la finitud y la infinitud con el objetivo de que lo definitivo pueda ir siendo vislumbrado en la transitoriedad.

El mutuo requerimiento de teología y mística se debe a la urgencia de poner vida y de sistematizar, de que la fe sea experiencia de encuentro con el resucitado, y que el cristiano que ha vivido el misterio se atreva a dar razón sin callar de su mística. Para ello el Espíritu Santo ilumina y puede hacernos trasparentes a su amor de modo que la transcendencia se vislumbre en la inmanencia. Así somos seres humanos que creados desde, por y para el amor podemos sistematizar una antropología teológica que da cuenta de lo eterno en lo histórico gracias a una racionalidad amorosa. Dicho pensar y amar interrelacionados va develando el misterio ("espanto") de lo humano, va dando atisbos de la finitud como asombro y sobrecogimiento para que vaya siendo posible encarnar lo definitivo en la transitoriedad.

Teresa siempre optimista tras las invitaciones se despide así:

"gozar de este castillo, en todas las cosas hallaréis descanso, aunque sean de mucho trabajo, con esperanza de tornar a él, que no os lo puede quitar nadie” (M Epilg 2). 